\title{
ANALYSIS OF BROME MOSAIC VIRUS REPLICATION AND AMINOACYLATION FUNCTIONS BY SITE- SPECIFIC MUTAGENESIS
}

\author{
TIMOTHY C. HALL, LOREN E. MARSH AND THEO W. DREHER \\ Biology Department, Texas AGM University, College Station, TX 77843-3258, USA
}

\section{SUMMARY}

Brome Mosaic Virus (BMV) has a tripartite RNA genome; each RNA and the subgenomic RNA encoding the viral coat protein share a highly homologous region of about 200 nucleotides at the $3^{\prime}$ end, for which a tRNA-like structure has been proposed. Several sequences encoding functions, including replicase binding, initiation of $(-)$ strand synthesis and tyrosine esterification are known to be nested within this region. Elongation factor EF- $1 \alpha$ binds to aminoacylated viral RNAs, but not to the uncharged forms. An additional function of the tRNA-like structure is to serve as a substrate for nucleotidyl transferase, which adds the terminal adenosine residue to the $(+)$ sense virion RNAs. A template-dependent and template-specific replicase preparation from BMVinfected barley leaves has been characterized and extensively used for replication studies in vitro that complement studies in vivo using protoplasts. The replicase has been shown to initiate de novo both $(-)$ strand synthesis on supplied $(+)$ strand RNAs, and $(+)$ strand subgenomic RNA synthesis on supplied (-) sense RNA3 templates. RNA transcripts obtained by transcription in vitro of cDNA clones containing desired base substitutions and deletions, have been supplied as templates for replication, aminoacylation and other assays. Use of such mutant RNAs has allowed the promoters for both (-) strand synthesis and for synthesis of the subgenomic $(+)$ strand RNA to be characterized and defined. The same approach has also been used to reveal regions of the tRNA-like structure involved in the tyrosylation of the BMV RNAs. These experiments showed that, although regions important in aminoacylation and replication functions overlap, they are not identical. Some of the mutations tested in vitro have also been tested for infectivity in vivo using. both barley plants and protoplasts. Mutants retaining replicase and nucleotidyl transferase template activity, but having lost aminoacylation capability are of special interest in that they should reveal the role of aminoacylation in the infection process.

\section{INTRODUCTION}

Viruses having an RNA genome cause the vast majority of viral infections of plants. As with animals, the onset of infection in plants typically occurs rapidly and depends upon successful multiplication of the invading genome within host cells. Despite the intensity of replication activity early in infection, it has proven remarkably difficult to elucidate the molecular events involved. Clearly, once introduced to a site of infection on or in the host by a suitable vector (Garrett et al. 1985), the viral RNA must be capable of entering the eukaryotic cell and diverting its metabolism to produce virally encoded macromolecules.

Brome mosaic virus (BMV) has an RNA genome consisting of RNA1 (3234 nucleotides (nt)), RNA2 (2865 nt) and RNA3 (2117 nt). A subgenomic component (RNA4, $876 \mathrm{nt}$ ), from which the coat protein is expressed, has a sequence colinear with the $3^{\prime}$ end of RNA3 (Ahlquist et al. 1981, 1984). A mixture of RNAs $1+2+3$ is 
infectious when rubbed onto the leaves of a suitable host (such as barley). RNAs 1 and 2 encode proteins ( $1 \mathrm{a}$ and $2 \mathrm{a}$ ) that are almost certainly involved in replication of BMV RNA. RNA 3 encodes two proteins: $3 a$, thought to be involved in cell-to-cell (systemic) spread of the virus, and a translationally silent copy of the coat protein gene.

The ability of the brome mosaic virus (BMV) genome to redirect biosynthetic functions in barley leaves is especially intriguing to us, and our investigations have centred principally on this host-pathogen system. Consequently, the present article focusses especially on the properties of the BMV-specific RNA-dependent RNA polymerase (replicase) and the way in which mutagenesis of viral RNA is being used to study host-virus interactions. For a broader view of replication strategies of RNA viruses the recent articles by Hall et al. (1982), Strauss \& Strauss (1983), van Kammen (1985), Hull \& Maule (1985), and Dreher \& Hall (1987a), are recommended.

\section{Replication of BMV RNA in vivo}

Although our research has not directly addressed the initial steps in natural infections of host plants by BMV, we have made extensive use of protoplast systems to follow early stages of infection. Protoplast systems are advantageous because defined amounts of inoculum can be supplied to a quantifiable number of relatively uniform host cells whose viability can be readily determined. BMV inoculum can be supplied either as nucleoprotein (virions) or as naked viral RNA; the latter is especially advantageous because there is no need to attempt encapsidation of mutagenized RNA sequences. Nevertheless, it is important to remember that protoplast systems do not mimic all aspects of infection processes in vivo, especially cell-to-cell transport. This is evident in the case of BMV which does not normally infect tobacco plants, but which is fully capable of infecting tobacco protoplasts ( $\mathrm{L}$. S. Loesch-Fries, personal communication). Differences between infections initiated with virions and with RNA are exemplified by their susceptibility to crossprotection. In the recent experiments of Abel et al. (1986) expression of tobacco mosaic virus (TMV) coat protein by the host plant was effective in delaying infection by virions, but gave no protection when RNA was used as inoculum. Despite these differences, the use of protoplasts permits analysis of early events following inoculation that are impossible to document in intact plants. Loesch-Fries \& Hall (1980) showed that new (labelled) RNAs 1 and 2 could be detected at $6 \mathrm{~h}$ postinoculation and RNAs 3 and $410 \mathrm{~h}$ post-inoculation. This observation is in accord with the belief that RNAs 1 and 2 are intimately involved in replication.

The barley protoplast system was also used by Kiberstis et al. (1981) to investigate which of the BMV RNA components were essential for replication. It was assumed that BMV replicase was entirely or partially comprised a virally encoded protein, and consequently that at least one of the BMV RNAs would have the property of being able to pass through the host protoplast membrane and serve as a messenger template for synthesis of the replicase or replicase component. Neither RNA3 nor RNA4 gave rise to detectable protein products when inoculated individually or in combination 
(RNAs $3+4)$. Tests for ribonuclease sensitivity of the inoculated RNA showed similar degrees of protection for each component, indicating that no preferential binding or plasmalemma transit characteristic exists that might have led to differential degradation of RNAs 3 or 4 over 1 or 2 .

Since RNA4 encodes the viral coat protein, it was not expected that it would itself function as the replicase. However, infections by other RNA viruses having a genomic organization similar to BMV, such as that caused by alfalfa mosaic virus, often require the presence of either coat protein or RNA4 (Ablas \& Bol, 1978). Consequently, it is remarkable that BMV virion RNA4 (an excellent $\mathrm{mRNA}$ in vitro: Pyne \& Hall, 1979; Kiberstis et al. 1981) is incapable of functioning as a mRNA when added to protoplasts, even at concentrations approaching $1 \mathrm{mg} \mathrm{ml}^{-1}$. This observation indicates either that virion RNA4 and newly replicated RNA4 (which is the active mRNA for coat protein synthesis once infection is established) differ in some subtle way, or that virion RNA4 is unable to reach a suitable subcellular location for its translation. Evaluation of such speculations will require detailed analysis at the subcellular level of the location of viral RNAs and proteins during the entire infection process.

RNAs $1+2$ were translated on addition to barley protoplasts, and yielded the expected polypeptide products 1a and 2a (Fig. 1). Replication of both RNAs was also evident in these experiments and many attempts were made to separate RNA1 from

1a $110 \times 10^{3} M_{\mathrm{r}}$

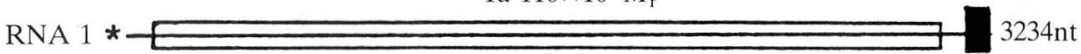

2a $105 \times 10^{3} M_{\mathrm{r}}$

RNA 2

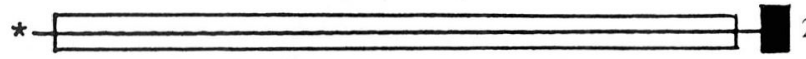

$2865 n t$

RNA 3

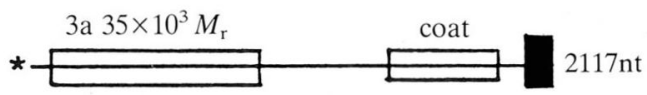

Subgenomic RNA 4

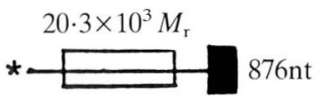

$\star^{7}$ mGppG cap

conserved $3^{\prime}$ end tRNA-like structure specifically binds tyrosine

Fig. 1. Genomic Organization of Brome Mosaic Virus (BMV). BMV is a $(+)$ sense RNA virus which encapsidates genomic RNAs that also function as mRNAs. BMV has a tripartite genome, RNAs 1 through 3. RNA4 is a subgenomic RNA derived from dicistronic RNA3. The open boxes represent the reading frames of the proteins translated from the RNAs, nt, nucleotides. 
RNA2; unfortunately, their similar sizes makes this extremely hard to accomplish by physical methods. Indeed, the protein synthesis observed in protoplasts inoculated with RNAs $1+2$ may be from newly replicated RNA, rather than from input RNA. These alternatives must be examined using RNAs 1 and 2 that can be translated but not replicated. However, when RNA1 or RNA2 was added in great excess over the contaminating component (RNA2 or RNA1), similar levels of each RNA (RNAs 1 and 2) were observed on analysis of the protoplasts (Kiberstis, 1982). This suggested that the protein products of both RNAs are intrinsically involved in replication. Confirmation of this situation has recently been afforded by experiments using pure samples of RNA1 and RNA2 obtained by transcription in vitro from cDNA clones (French et al. 1986); no replication occurs unless both RNAs are present in the inoculum. Sequences are now available for several RNA-dependent polymerases and viral genomes; comparison of such sequences reveals that BMV RNA2 contains regions of homology with RNA-dependent polymerases from plant, animal and bacterial viruses (Kamer \& Argos, 1984), and it is thus almost certain that polypeptide $2 \mathrm{a}$ is a core component of the viral replicase.

\section{Isolation and characterization of BMV replicase}

In describing the replicase and its products, a clear understanding of terminology is important. Multiplication of viral RNA involves several steps, beginning with initiation of new (-) strand synthesis at the $3^{\prime}$ end of the supplied (+ sense, virion) RNA and followed by initiation and synthesis of new $(+)$ strands from the recently formed (-) strand. The template-dependent polymerization of nucleoside triphosphates, including elongation of established chains, is a polymerase characteristic. We believe that replication should be reserved for the entire cycle of supplied $(+)$ to new $(+)$ strand formation and consequently that an enzyme preparation must be capable of both (-) and (+) strand synthesis to be termed a replicase. In the case of subgenomic RNAs, such as BMV RNA4, the replicase preparation exhibits an additional property; that of recognizing an initiation site internal to the genomic component. Synthesis of RNA strands from DNA templates is appropriately termed transcription and the products are termed transcripts. Although the synthesis of RNA strands from RNA templates is typically called replication, there is no generally accepted terminology for the products; they are typically called transcripts although 'repliscripts' would be more consistent. The reason for preferring such terminology will become apparent later in this article where RNA transcripts (obtained by bacteriophage SP6, T7 or T3 promoter-driven transcription of cDNA clones) are used as templates for replication. However, to avoid introducing new terminology, the RNA copies derived as a result of replication are called 'products' in this.article; hopefully this will prevent confusion arising from stating that 'transcripts give rise to transcripts'.

When one considers the importance of replication in viral aetiology, it is not surprising that many articles exist describing attempts to isolate replicases from plants. We have reviewed previously (Hall et al. 1982; Miller \& Hall, 1984) the pitfalls associated with interpretation of data based on incorporation of nucleoside 
triphosphates into acid precipitable material rather than on characterized products of replicase assays. Consequently, this aspect will not be dwelt on here, other than to note that reactions that have nothing to do with the viral replication process, such as those catalysed by terminal transferase and by the ubiquitous (but enigmatic) host RNA polymerase can yield labelled RNA products. In devising our strategy for studying BMV replication we have consistently demanded that the extracts from infected plants exhibit template-dependency and template-specificity for BMV RNAs. In common with other investigators who have isolated viral RNA-dependent RNA polymerases from plants, we find that only fractions associated with plant membranes exhibit these properties. Treatment with organic solvents (ether, carbon tetrachloride) or strong detergents (Triton X-100) results in solubilization of activity, but template specificity is invariably lost. Experiments by Bové and colleagues (Mouchès et al. 1974, 1984) using the non-ionic detergent Lubrol WX for extraction of replicase from turnip yellow mosaic virus-infected chinese cabbage plants showed great promise, but precise characterization of the products is still awaited. Hardy et al. (1979) showed that Nonidet P-40, also a non-ionic detergent, yielded template-specific and partially template-dependent replicase fractions from BMV-infected barley plants. Substitution of dodecyl $\beta$-D-maltoside for Nonidet P-40 (Bujarski et al. 1982) improved activity of the system, and had the significant attribute that extracts could be stored for several months before template activity or specificity was lost. Fig. 2 Describes our current protocol for BMV replicase isolation: This includes limited digestion of the replicase preparation with micrococcal nuclease since this treatment was found (Miller et al. 1983) to yield a highly template-dependent (and specific) enzyme.

Improvements remain to be made in the isolation of BMV replicase. The enzyme presently used (Fig. 2) contains many proteins that are present in the membrane extract which have nothing to do with viral replication. BMV RNA1-encoded protein la was readily visible among the polypeptides separated by electrophoresis of the replicase preparation. Protein 1a is difficult to detect in separations of total leaf proteins (Kiberstis et al. 1981) and this observation suggests that the replicase preparation is enriched in protein 1a. Clearly, the presence of protein 1a does not constitute proof of function. Protein 2a was not detected among the polypeptides, but this does not exclude its presence or functionality. It is more than likely that further partition with non-ionic detergents would enhance the purity of the enzyme. However, we are cautious in this respect since many 'highly purified' replicase preparations (Kumarasamy \& Symons, 1979; Dorssers et al. 1983) are incapable of initiation on supplied template and consequently can have only partial relevance to the true replication process. The BMV replicase is also relatively inefficient; considerably less than $1 \%$ of the input template is copied to yield products.

Despite the shortcomings noted above, the replicase preparation shown in Figure 2 has attributes that verify its involvement in BMV replication. These were detailed previously by Miller et al. (1986) who provided conclusive demonstration of de novo initiation on supplied template (through the incorporation of supplied $\gamma\left[{ }^{32} \mathrm{P}\right] \mathrm{GTP}$ ) and confirmation by direct sequencing of the product RNA that the supplied 


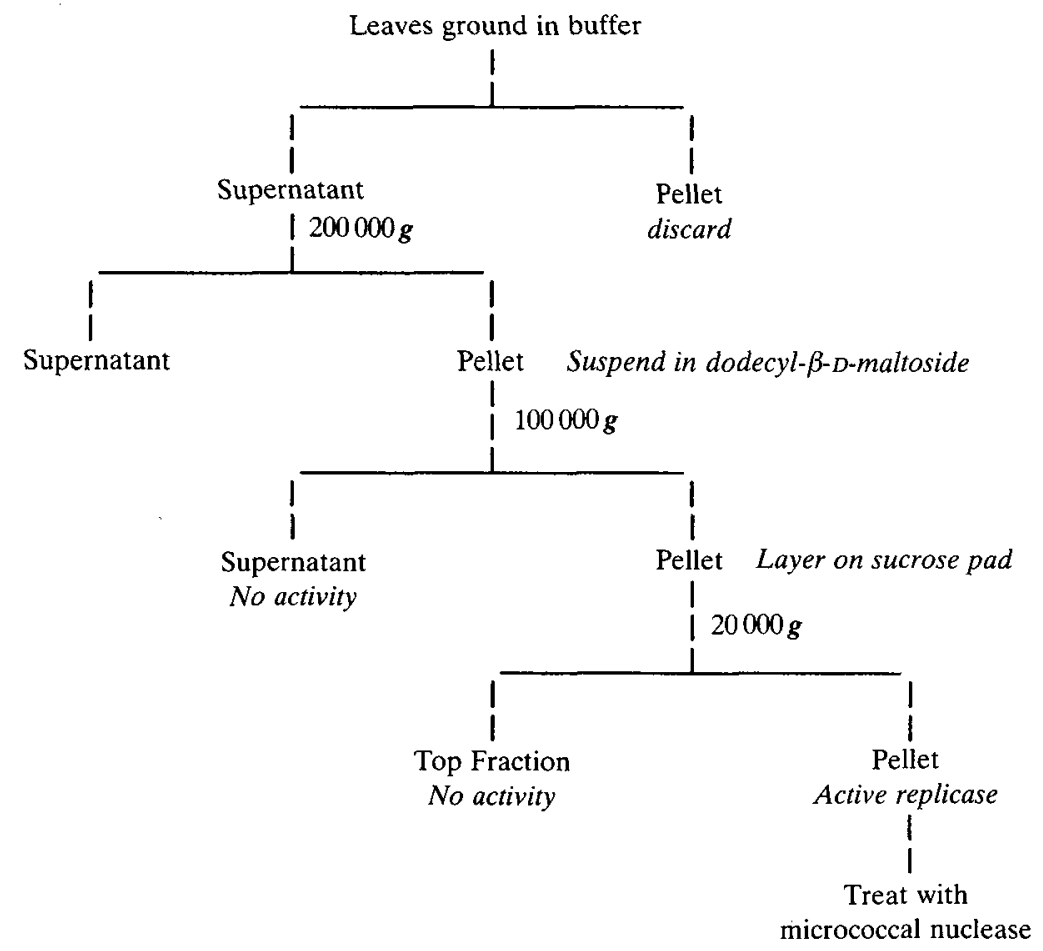

Fig. 2. BMV replicase (RNA-dependent RNA polymerase) extraction procedure. As shown, a series of differential centrifugation steps was used to isolate replicase from BMV-infected barley (for details see Bujarski et al. 1982). The use of a nonionic detergent, dodecyl- $\beta$-D-maltoside permitted removal of many contaminating proteins from the membrane fraction without loss of specificity for BMV RNA templates. The final replicase preparation was relatively free of endogenous nuclease activity allowing use of exogenous RNA template. Micrococcal nuclease treatment degraded endogenous viral RNA making the replicase activity dependent on the exogenous RNA template (Miller \& Hall, 1983).

template is copied. Additional aspects of its functional characterization are detailed below in respect to the use of mutant BMV RNA templates.

\section{Hybrid-arrested replication of BMV RNA 3'-terminal fragments}

It cannot be stressed too strongly that the isolation of a template-dependent and template-specific replicase was seen as an essential prerequisite to studying replicase binding and initiation at the molecular level. Using the replicase preparation described above, several experiments were conducted with BMV RNA fragments that were hybridized with single stranded cDNA sequences (Ahlquist et al. 1984a). These experiments revealed that obstruction of the $3^{\prime}$ terminus by hybrid formation inhibited replication, presumably by preventing initiation. When cDNA sequences complementary to internal regions of the $3^{\prime}$ end of BMV RNA were hybridized, replication was frequently unaffected, indicating that the replicase can pass through certain double-stranded regions. This attribute is important since it is clear that some regions of both the $(+)$ and $(-)$ strands of the BMV RNAs have quite extensive 
secondary and tertiary structure. However, hindrance of replication was apparent from some of the internal hybrids, and it seemed likely that these locations were candidates for sites recognized by the replicase for binding to the template. However, it was also apparent that extrapolation of the hybridization approach was unsatisfactory since many regions of the 3 ' end were inaccessible for hybridization. In any case, it could never provide adequate resolution for our studies, for example in the comparison of the effect of sequence versus structural alterations by the introduction of transitions, transversions, single base changes and deletions. In contrast, the use of BMV RNA transcripts synthesized in vitro offered potentially unlimited opportunities for modified templates that facilitate elucidation of many viral functions, including replication and aminoacylation.

\section{Replication of mutated BMV RNA templates in vitro}

The advent of efficient systems for transcription in vitro from cDNA templates (Green et al. 1983) offered the opportunity to synthesize RNA sequences containing specific mutations or deletions. A series of cDNA clones that covered the common $3^{\prime}$ terminal 200 nucleotides of the BMV RNAs were constructed that contained mutations in either the presumed anticodon region ( $\operatorname{arm~C}$ of Fig. 3) or the two $3^{\prime}$ terminal nucleotides (Dreher et al. 1984). The anticodon region was of special interest since, as will be discussed below, the BMV RNAs can be specifically esterified with tyrosine (Hall et al. 1972). In some tRNAs the anticodon interacts with the tRNA synthetase and it was thought possible that alteration of the anticodon sequence would affect the aminoacylation function of the transcribed RNA. However, single base substitutions of either the $5^{\prime}$-most nucleotide or the central nucleotide of the anticodon resulted in over $80 \%$ loss of replicase template function (compared with that of a wild-type transcript) whereas aminoacylation was affected by less than $10 \%$ even when nucleotides in both positions were substituted. These results delineated arm $\mathrm{C}$ as being involved in replicase binding and strongly suggested that it had little function in aminoacylation. Indeed, subsequent experiments in which the small unpaired 'knob' region (4 nucleotides) on this arm (see Fig. 3) was deleted (Dreher \& Hall, 1986), or in which large (54 nucleotide) deletions were made (Bujarski et al. 1985), also resulted in relatively little change in aminoacylation function, but effectively eliminated replicase template activity.

As was to be expected, mutation of the 3 -terminal two nucleotides drastically reduced replicase template activity and eliminated the tyrosine acceptance function. Because repair of the $3^{\prime}$-CCA terminus with nucleotidyl transferase occurs (see below) these modifications are likely to be corrected in vivo, although this remains to be tested. Careful analysis of $(-)$ strand products by a chain-termination procedure, and by incorporation of $\left[\gamma_{-}{ }^{32} \mathrm{P}\right] \mathrm{GTP}$ (Miller et al. 1986), showed that initiation of (-) strand synthesis occurred opposite the C-2 (less likely, the C-3) nucleotide of the $(+)$ strand. This was confirmed using RNAs subjected to one, two, or three cycles of $\beta$-elimination as replicase templates (Miller et al. 1986). RNAs terminating in -GACCA (wild-type) or -GACC were equally active templates, but RNAs terminating in -GAC or -GA were inactive. Experiments in which the $3^{\prime}$ terminus of the $(+)$ 
strand was extended with poly(A) sequences or oligonucleotide sequences have shown that limited extensions are not totally inhibitory to replication, but that the C-2 initiation site is specifically maintained. BMV RNA templates containing oligonucleotide extensions 6 bases beyond the normal -CCA terminus were as active as wild-type RNA in (-) strand initiation in vitro; extensions 15 bases long were, however, inactive (Miller et al. 1986).

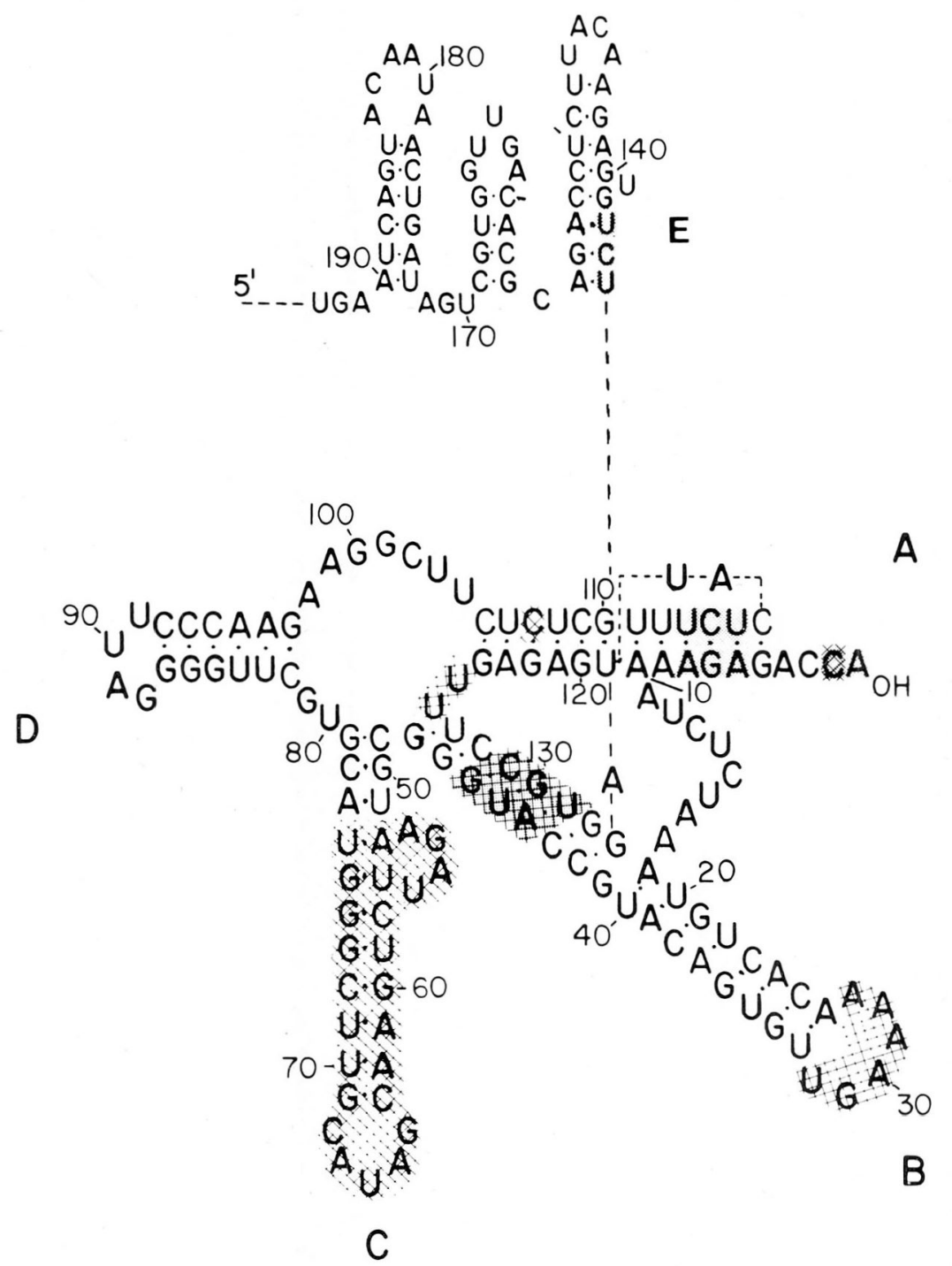

Fig. 3. The conserved $3^{\prime}$ region of BMV $(+)$ strand RNAs including the tRNA-like structure. Mutations have been used to map the regions of the $3^{\prime}$ ends important in vitro in aminoacylation (cross-hatched) and replication (stippled) (Dreher et al. 1984, Bujarski et al. 1985, Dreher \& Hall, 1987b). The tRNA-like structure consists of arms A through $\mathrm{D}$, although arm $\mathrm{E}$ is also involved in aminoacylation. 
Site-directed mutagenesis of all major regions of the $3^{\prime}$ structure have now been constructed. These show widespread interaction of the replicase within this region (Fig. 3). However, 3' fragments 134 nucleotides in length (obtained by ribonuclease$\mathrm{H}$ cleavage: Miller et al. 1986) have similar levels of template function to $3^{\prime}$ sequences 200 nucleotides long and it is therefore unlikely that the replicase interacts with sequences beyond the tRNA-like structure to initiate (-) strand synthesis.

\section{Aminoacylation of BMV RNA}

The RNA components of several groups of plant viruses are capable of accepting amino acids (Hall, 1979; Haenni et al. 1982). The reaction is specific for a given amino acid and, in the cases where kinetics of the reaction have been measured (Hall et al. 1972; Giegé et al. 1978), they are similar to values obtained for aminoacylation of tRNAs. Among the several possible roles for aminoacylation in the infection process is a function in replication (Litvak et al. 1973; Hall \& Wepprich, 1976). This is suggested by analogy with $\mathrm{Q} \beta$ replicase which contains the bacterial host elongation factors EF-Tu.Ts as part of the complex (Blumenthal et al. 1972). Since, as in the case of tRNAs, elongation factor binds only to aminoacylated viral RNAs (Bastin \& Hall, 1976), aminoacylation of viral RNA could assist in binding of part of the replication complex. This might be especially useful in early stages of infection when the inoculum is in low concentration. Recent experiments using EF- $1 \alpha$-specific antibody have failed to show the presence of eukaryotic EF-1 $\alpha$ in turnip yellow mosaic virus replicase (Joshi et al. 1986), but similar tests revealed its presence in the BMV replicase (unpublished observations). As in the case of virally encoded proteins (see above), the presence of a given polypeptide in the replicase fraction does not confirm a functional role.

One objective of our experiments has been to determine if the regions of the $3^{\prime}$ terminus of BMV RNAs recognized by replicase and synthetase are identical. If mutation or deletion of sequences within the tRNA-like structure invariably affected both reactions, this would provide strong evidence for interdependence of these functions. Discrimination between these functions was evident from the experiments described above in which the putative tyrosine anticodon was mutated (Dreher et al. 1984) and substitutions and deletion of sequences in other regions of the tRNA-like structure was also found to differentially affect aminoacylation and replication in vitro (Bujarski et al. 1985; Dreher and Hall, unpublished; Fig. 3). Although it is clear that in vitro there is no requirement for aminoacylation of the BMV RNA template for it to function as a replicase template, this does not preclude a direct involvement in vivo of aminoacylation in replication.

\section{Nucleotidyl transferase interaction with BMV RNAs}

The participation of nucleotidyl transferase in valylation of TYMV RNA (Pinck et al. 1970) was evident since the virion RNA terminates in -CC and the formation of a -CCA terminus is neccessary for aminoacylation. In the case of $B M V$, the role of nucleotidyl transferase is less obvious since virion RNA terminates with -CCA. However, nearest neighbour analysis of double-stranded BMV RNA3 (from infected 
barley plants) $3^{\prime}$ labelled with $\left[5^{\prime}-{ }^{32} \mathrm{P}\right] \mathrm{pCp}$ showed that the majority $(72 \%)$ of $(+)$ and $(-)$ strands terminated with $-\mathrm{C}$; only $4 \%$ terminated in -A (Miller et al. 1986). This evidence, plus the initiation of $(-)$ strand synthesis with pppG (not pppU), requires the addition of the $3^{\prime}$-terminal $-A$ of the virion RNA to be a non-templated event. Such considerations indicate that the $3^{\prime}$-terminal structure of BMV RNAs interacts with nucleotidyl transferase as well as replicase and synthetase, and the various mutants are now being tested for their ability to be adenylated. It is important to appreciate that the RNA transcripts obtained in vitro from cDNAs containing site-directed mutations will bear a $3^{\prime}$-terminal - $A$ if the complementary residue $(T)$ is present in the $c D N A$ template, eliminating the need for nucleotidyl transferase activity in adding this residue. The ability of the mutant sequences to interact with nucleotidyl transferase must therefore be tested by removal of the A residue (by $\beta$-elimination or phosphodiesterase treatment) and testing the ability of nucleotidyl transferase to repair the -CCA terminus.

\section{Tests in vivo for infectivity of mutant BMV RNA sequences}

It was clearly important that predictions obtained by tests in vitro should be confirmed in vivo. The opportunity provided by recombinant DNA techniques to undertake such tests provides a novel approach to identifying the roles of various viral functions in the infection process. For example, if mutants are constructed that are capable of near normal levels of replication and adenylation function, but greatly reduced in aminoacylation function, are found to be non-infectious, this will strengthen the case for the aminoacylation function having a vital role in infectivity. Several of the BMV RNA mutations reported by Bujarski et al. (1985) were especially attractive for such tests since increased as well as decreased activities were observed (Table 1). Deletions that showed greatly reduced replicase activity in vitro were deemed unlikely to be viable and infectivity tests using full length BMV RNA3 transcripts containing the D2, M5 and S1 deletions failed to show any infectivity when inoculated together with wild type transcripts of RNAs 1 and 2 onto barley protoplasts. BMV RNA3 transcripts incorporating deletion X6, which yielded $70 \%$

Table 1. Influence of various deletions in BMV RNA $3^{\prime}$ fragments on aminoacylation, adenylation and (-) strand synthesis in vitro and infectivity in vivo

\begin{tabular}{lcccccc}
\hline $\begin{array}{l}\text { Deletion } \\
\text { name }\end{array}$ & $\begin{array}{c}\text { Bases } \\
\text { removed }\end{array}$ & $\begin{array}{c}\text { Arms } \\
\text { affected* }\end{array}$ & $\begin{array}{c}\text { Adenylation } \\
\text { Replication }\end{array}$ & $\begin{array}{c}\text { Aminoacylation } \\
\text { Infectivity }\end{array}$ \\
\hline wt & & & 100 & 100 & 100 & + \\
M4 & $81-100$ & D & 250 & 200 & 100 & + \\
X6 & $127-148$ & B & 40 & 70 & 5 & - \\
D2 & $58-91$ & C,D & 10 & 0 & 55 & - \\
M5 & $76-104$ & C,D & 2 & 5 & 72 & - \\
S1 & $86-196$ & A,B,D & 0 & 0 & 0 & -
\end{tabular}

* Refer to Fig. 3 for definition of helical arms A-D in the $3^{\prime}$ terminal 133 bases of BMV RNA3. Adapted from Bujarski et al. 1985; Bujarski et al. 1986.

$\mathrm{wt}=$ wild type. 
of the wild type replicase template activity but only $5 \%$ of the wild type aminoacylation function were also non-infectious. However, the capacity for X6 transcripts to be adenylated in vitro was also reduced, being only $40 \%$ of the wild type activity. Consequently, the lack of infectivity may be due to loss of adenylation function rather than to loss of aminoacylation function. Deletion M4, which mimics the structure of broad bean mottle virus RNA (Ahlquist et al. 1981), was found by in vitro tests to be twice as active a template for $(-)$ strand synthesis and over twice as active a template for adenylation. When included in the inoculum, BMV RNA3 transcripts containing the M4 deletion (BMV M4 RNA3) were infectious and progeny RNAs from both protoplasts and barley plants were shown to retain the deletion. However, the ratio of M4 RNA3 to RNAs 1 and 2 was generally lower than that for wild type RNA3. This suggests that although the M4 deletion yields higher levels of $(-)$ strand synthesis in vitro, it may interfere with other viral functions in vivo. Indeed, progeny RNA3 from barley plants that were harvested 10-15 days after inoculation were shown to have undergone recombination events that resulted in the deletion being replaced by wild type sequences from RNAs 1 or 2 (Bujarski \& Kaesberg, 1986), suggesting that strong selection pressure against the M4 deletion exists in vivo.

\section{Synthesis of subgenomic BMV RNA4}

The ability of the replicase preparation to initiate and faithfully copy supplied exogenous templates provided the opportunity to examine the mechanism for. generating subgenomic RNA4. Bancroft \& Lane (1973) showed by genetical analysis that BMV coat protein was determined by the coat protein gene in RNA3, not by subgenomic RNA4 in the inoculum. However, the coat protein cistron on RNA3 is silent in cell-free protein synthesis, or when injected into Xenopus oocytes (D. R. Talbot and L. S. Loesch-Fries, personal communication), whereas RNA4 is an efficient mRNA in these systems. Subgenomic RNAs are a common feature of plant, and some animal, viruses; several theories concerning their derivation have been advanced. These include: internal initiation on the $(-)$ strand of genomic RNA (Kennedy, 1980; Nassuth et al. 1981); premature termination during (-) strand synthesis, followed by independent replication of the subgenomic RNA (Goelet \& Karn, 1982) and nuclease processing of genome-length RNA (Gonda \& Symons, 1979). Using the BMV replicase, Miller et al. (1985) showed unequivocally that subgenomic RNA4 was synthesized from $(-)$ strand templates of BMV RNA3. It was evident from these studies that BMV replicase binds upstream of the RNA4 initiation site on RNA3, and hence that (-) strand RNA4 cannot serve as a template for new $(+)$ strand synthesis.

We are currently characterizing the subgenomic promoter region to learn what features are especially important to its function. The RNA sequence upstream of the initiation site bears no resemblance in structure or sequence to the tRNA-like $3^{\prime}$ end of the $(+)$ strand that serves as a promoter for $(-)$ strand synthesis. A restriction map of this region is shown in Fig. 4. Truncated (-) RNA3 replicase templates and deletion mutants have been used to define the core sequence of the subgenomic 


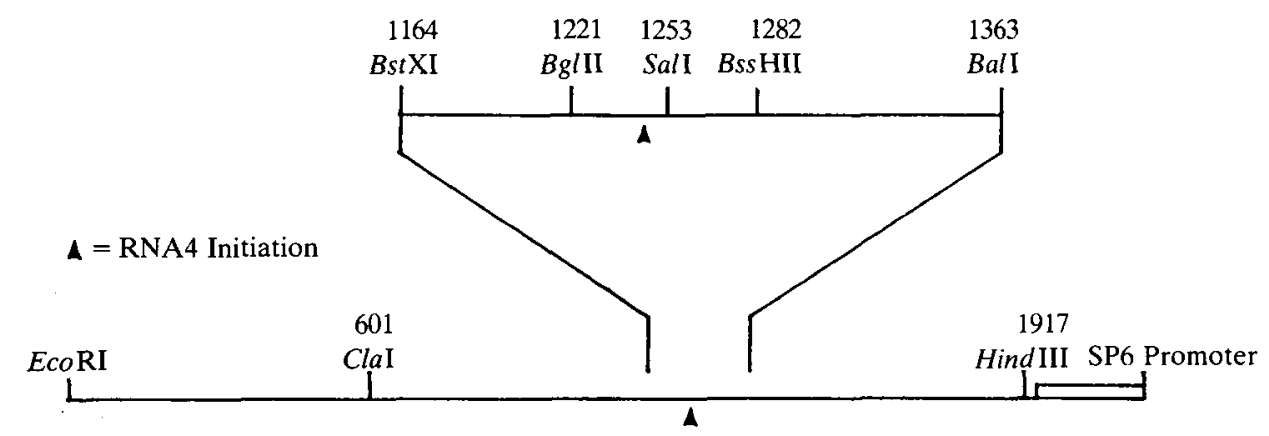

Fig. 4. Restriction map of the subgenomic promotor region of the BMV RNA3 cDNA transcriptional plasmids and M13 phage. The relevant restriction sites of the cDNA of BMV RNA3 are shown above with the numbering of the bases corresponding to (+) RNA3. The region of the plasmid surrounding the subgenomic promoter has been expanded. The (-) RNA3 transcript is obtained from these plasmids using either SP6 or T7 RNA polymerase. The subgenomic promoter core sequence is located immediately upstream of the initiation site for RNA4 within the 32 bases between the $B g l \mathrm{II}$ and the SalI sites (Marsh et al. 1987).

promoter as lying between the $B g l \mathrm{II}$ and SalI sites (at nucleotides 1221 and 1253, respectively: Marsh et al. 1987). Experiments with barley protoplasts in which chloramphenicol acetyltransferase (CAT) was expressed in place of the coat protein also indicate that the core sequence of the subgenomic promoter is upstream of the Sal I site (French et al. 1986). The in vivo approach is less applicable for defining the essential sequences of the subgenomic promoter in that the intergenic region is probably involved in replication of RNA3 (unpublished observations) and in vivo the effects of mutations on production of subgenomic RNA4 would be difficult to distinguish from their effects on maintenance of the genomic RNA3. Comparison of the core sequence of the BMV RNA subgenomic promoter with those of the putative subgenomic promoters of other plant (tobacco rattle virus, cucumber mosaic virus, alfalfa mosaic virus) and animal (alphavirus) (+)-stranded viral RNAs has revealed considerable homology (Marsh et al. 1987; Ou et al. 1982).

\section{Status and future prospects}

The preceding reviews the present state of knowledge regarding replication of BMV RNA. Considerable advances have been possible through the use of the in vitro replicase system in conjunction with mutant transcripts synthesized from cDNAs, and expression in vivo of BMV RNA transcripts containing mutated sequences is also proving to be most revealing in regard to viral mechanisms. The replicase system has been used in vitro to reveal features essential to the initiation and synthesis of $(-)$ strand RNAs and $(+)$ strand subgenomic RNAs. However, attempts to show genomic $(+)$ strand synthesis from full-length copies of $(-)$ strand RNAs have thus far been unsuccessful. Correctly terminated (-) RNA3 has not been an active template for full-length $(+)$ strand synthesis. This may be due to a requirement for an additional $3^{\prime} \mathrm{G}$ residue at the $3^{\prime}$. terminus of the $(-)$ strand (Collmer \& Kaper, $1985)$, or may reflect a deficiency in the activity of the replicase preparation. 
Very recently, we (Marsh \& Hall, 1988) have recognized homologies between sequences at the $5^{\prime}$ ends of all BMV RNAs and the internal control regions (ICRs 1 and 2, also known as $\mathrm{A}$ and $\mathrm{B}$ boxes) of tRNA promoters. Consequently, the potential role for polymerase III-like activities in the replication of BMV (and related virus RNAs) deserves future scrutiny.

The relatively crude state of the BMV replicase we use is disturbing, although less so than the fact that some 'purified' replicase preparations are entirely unable to initiate on exogenously supplied template and are thus lacking in a vital characteristic. It would be more satisfactory to have higher levels of activity, and a better useage of the supplied template. Hopefully, further purification of the replicase complex will result in improving these features, and assist in further elucidating the molecular biology of BMV RNA replication.

This work was supported by N.I.H. grant AI 22354, NATO Grant RG.85/0494 (to T.W.D.) and by the Texas A\&M Office of University Research.

\section{REFERENCES}

Abel, P. P., Nelson, R. S., De, B., Hoffmann, N., Rogers, S. G., Fraley, R. T. \& Beachy, R. N. (1986). Delay of disease development in transgenic plants that express the tobacco mosaic virus coat protein gene. Science 232, 738-743.

ABLAS, F. \& Bol, J. F. (1978). Coat protein is required for infection of cowpea protoplasts with alfaifa mosaic virus. F. gen. Virol. 14, 653-656.

Ahlquist, P., Bujarski, J. J., Kaesberg, P. \& Hall, T. C. (1984a). Localization of the replicase recognition site within brome mosaic virus RNA by hybrid-arrested RNA synthesis. Plant Molec. Biol. 3, 37-44.

Ahlquist, P., DAsGupta, R. \& Kaesberg, P. (1981). Near identity of 3' RNA secondary structure in bromoviruses and cucumber mosaic virus. Cell 23, 183-189.

Ahlquist, P., DAsgupta, R. \& Kaesberg, P. (1984). Nucleotide sequence of the brome mosaic virus genome and its implications for viral replication. $\mathcal{F}$. mol. Biol. 172, 369-383.

Ahlquist, P., Luckow, V. \& Kaesberg, P. (1981). Complete nucleotide sequence of brome mosaic virus RNA3. F. mol. Biol. 153, 23-28.

BANCROFT, J. B. \& LANE, L. C. (1973). Genetic analysis of cowpea chlorotic mottle and brome mosaic viruses. F. gen Virol. 19, 381-389.

Bastin, M. \& HALL, T. C. (1976). Interaction of elongation factor 1 with aminoacylated brome mosaic virus and tRNAs. F. Virol. 20, 117-122.

Blumenthal, T., Landers, T. A. \& Weber, K. (1972). Bacteriophage Q $\beta$ replicase contains the protein synthesis elongation factors EF-Tu and EF-Ts. Proc. natn. Acad. Sci. U.S.A. 69, $1313-1317$.

Bujarski, J. J., Ahlquist, P., Hall, T. C., Dreher, T. W. \& Kaesberg, P. (1986). Modulation of replication, aminoacylation and adenylation in vitro and infectivity in vivo of BMV RNAs containing deletions within the multifunctional $3^{\prime}$ end. EMBO. $\mathcal{F} .5,1769-1774$.

Bujarski, J. J., Dreher, T. W. \& Hall, T. C. (1985). Deletions in the 3 '-terminal tRNA-like structure of brome mosaic virus RNA differentially affect aminoacylation and replication in vitro. Proc. natn. Acad. Sci. U.S.A. 82, 5636-5640.

Bujarski, J. J., Hardy, S. F., Miller, W. A. \& Hall, T. C. (1982). Use of dodecyl- $\beta$-Dmaltoside in the purification and stabilization of RNA polymerase from brome mosaic virusinfected barley. Virology 119, 465-473.

BUJARSKI, J. J. \& KAESBERG, P. (1986). Genetic recombination between RNA components of a multipartite plant virus. Nature, Lond. 321, 528-531.

Collmer, C. W. \& KAPER, J. M. (1985). Terminal sequences of the double-stranded RNAs of cucumber mosaic virus and its satellite: Implications for replication. Virology 145, 249-259. 
Dorssers, L., van der Meer, J., van Kammen, A. \& Zabel, P. (1983). The cowpea mosaic virus RNA replication complex and the host-encoded RNA- dependent RNA polymerase-template complex are functionally different. Virology 125, 155-174.

Dreher, T. W., Bujarski, J. J. \& Hall, T. C. (1984). Mutant viral RNAs synthesized in vitro show altered aminoacylation and replicase template activities. Nature, Lond. 311, 171-175.

Drener, T. W. \& HALL, T. C. (1987a). Replication of BMV and related viruses. In RNA Genetics (ed. J. H. Holland, D. Esteban \& P. Ahlquist), Boca Raton: CRC Press, Florida (in press).

Dreher, T. W. \& HaLL, T. C. (1987b). Mutational analysis of the functions of the tRNA-like region of brome mosaic virus. In Positive Strand RNA Viruses (ed. M. A. Brinton \& R. R. Rueckert), U.C.L.A. Symposium Series, 54, pp. 317-325. New York: Alan R. Liss Inc.

FrenCH, R., JANDA, M. \& AHLQUist, P. (1986). Bacterial gene inserted in an engineered RNA virus: efficient expression in monocotyledonous plant cells. Science 231, 1294-1297.

Garrett, R. G., Cooper, J. A. \& SMith, P. R. (1985). Virus epidemiology and control. In The Plant Viruses I. Polyhedral Vinions with Tripartite Genomes (ed. R. I. B. Francki), pp. 269-297. New York: Plenum Press.

Giegé, R., Briand J-P Mengual, R. \& Ebel J.-P. and Hirth, L. (1978). Valylation of the two RNA components of turnip-yellow mosaic virus and specificity of the tRNA aminoacylation reaction. Eur. F. Biochem. 84, 251-256.

GoElet, P. \& KARN, J. (1982). Tobacco mosaic virus induces the synthesis of a family of 3' coterminal messenger RNAs and their complements. F. molec. Biol. 154, 541-550.

GONDA, T. J. \& SyMONS, R. H. (1979). Cucumber mosaic virus replication in cowpea protoplasts: Time course of virus, coat protein and RNA synthesis. F. Gen. Virol. 45, 723-736.

Green, M. R., Maniatis, T. \& Melton, D. A. (1983). Human $\beta$-globin pre-mRNA synthesized in vitro is accurately spliced in Xenopus oocyte nuclei. Cell 32, 681-694.

Haenni A-L Joshi, S. \& Chapeville, F. (1982). tRNA-like structures in the genomes of RNA viruses. Prog. Nucl. Acids Res. mol. Biol. 27, 85-104.

Hall, T. C. (1979). Transfer RNA-like structures in viral genomes. Int. Rev. Cytol. 60, 1-26.

Hall, T. C., Miller, W. A. \& BujARSKi, J. J. (1982). Enzymes involved in the replication of plant viral RNAs. In Advances in Plant Pathology (ed. D. S. Ingram \& P. H. Williams), 1, pp. 179-211. Academic Press.

HALL, T. C., SHIH, D. S. \& KAESBERG, P. (1972). Enzyme-mediated binding of tyrosine to bromemosaic-virus ribonucleic acid. Biochem. Э. 129, 969-976.

HALL, T. C. \& WePPRICH, R. K. (1976). Functional possibilities for aminoacylation of viral RNA in transcription and translation. Ann. Microbiol. 127A, 143-152.

Hardy, S. F., German, T. L., Loesch-Fries, L. S. \& Hall, T. C. (1979). Highly active template-specific RNA-dependent RNA polymerase from barley leaves infected with brome mosaic virus. Proc. natn. Acad. Sci. U.S.A. 76, 4956-5960.

Hull, R. \& Maule, A. J. (1985). Virus multiplication. In The Plant Viruses; 1. Polyhedral virions with tripartite genomes (ed. R. I. B. Francki), pp. 83-115. New York: Plenum Press.

Joshi, R. L., RAVEL, J. M. \& HAENNI, A.-L. (1986). Interaction of turnip yellow mosaic virus valRNA with eukaryotic elongation factor EF-1a. Search for a function. EMBO F. 5, 1143-1148.

Kamer, G. \& ARgos, P. (1984). Primary structural comparison of RNA-dependent polymerases from plant, animal and bacterial viruses. Nucl. Acids Res. 12, 7269-7282.

Kennedy, S. I. T. (1980). In The Togaviruses (ed. R. W. Schlessinger), pp. 351-369. New York: Academic Press.

KIbERSTIS, P. A. (1982). Viral protein and RNA synthesis in barley protoplasts inoculated with native, fractionated, and chemically-modified brome mosaic virus RNA. Ph.D. Thesis, University of Wisconsin-Madison.

Kiberstis, P. A., Loesch-Fries, L. S. \& Hall, T. C. (1981). Viral protein synthesis in barley protoplasts inoculated with native and fractionated brome mosaic virus RNA. Virology 112, 804-808.

Kumarasamy, R. \& Symons, R. H. (1979). Extensive purification of the cucumber mosaic virusinduced RNA replicase. Virology $96,622-632$.

Litvak, S., Tarrago, A., Tarrago-Litvak, L. \& Allende, J. E. (1973). Elongation factor-viral genome interaction dependent on the aminoacylation of TYMV and TMV RNAs. Nature New Biol. 241, 88-90. 
Loesch-Fries, L. S. \& HALl, T. C. (1980). Synthesis, accumulation and encapsidation of individual brome mosaic virus RNA components in barley protoplasts. F. Gen. Virol. 47, 323-332.

MARSH, L. E., DrehER, T. W. \& HALL, T. C. (1987). Mutational analysis of the internal promoter for transcription of the subgenomic RNA4 of BMV. In Positive Strand RNA Viruses (ed. M. A. Brinton \& R. R. Rueckert), U.C.L.A. Symposium Series, 54, pp. 327-336. New York: Alan R. Liss Inc.

MARSH, L. E. \& HALL, T. C. (1988). Evidence implicating a tRNA heritage for the promoters of (+) strand RNA synthesis in brome mosaic and related viruses. In The Evolution of Catalytic Function. Cold Spring Harbor Symposium on Quantitative Biology, 52. New York: Cold Spring Harbor Laboratory (in press).

Miller, W. A., Bujarski, J. J., Dreher, T. W. \& Hall, T. C. (1986). Minus-strand initiation by brome mosaic virus replicase within the $3^{\prime}$ tRNA-like structure of native and modified RNA templates. F. molec. Biol. 187, 537-546.

Miller, W. A., Dreher, T. W. \& Hall, T. C. (1985). Synthesis of brome mosaic virus subgenomic RNA in vitro by initiation on (-)-sense genomic RNA. Nature, Lond. 313, 68-70.

Miller, W. A. \& Hall, T. C. (1983). Use of micrococcal nuclease in the purification of highly template-dependent RNA-dependent RNA polymerase from brome mosaic virus infected barley. Virology 125, 236-241.

Miller, W. A. \& HALl, T. C. (1984). RNA-dependent RNA polymerase isolated from cowpea chlorotic mottle virus-infected cowpeas is specific for bromoviral RNA. Virology 132, 53-60.

Mouchès, C., BovE, C. \& Bové, J. M. (1974). Turnip Yellow Mosaic Virus RNA-replicase: Partial purification of the enzyme from the solubilized enzyme-template complex. Virology 58, 409-423.

Mouchès, C., CANdresse, T. \& Bové, J. M. (1983). Turnip yellow mosaic virus RNA-replicase contains host and virus-encoded subunits. Virology 134, 78-90.

Nassuth, A., Alblas, F. \& Bol, J. F. (1981). Localization of genetic information involved in the replication of alfalfa mosaic virus. F. Gen. Virol. 53, 207-214.

Ou, J. H., Rice, C. M., Dalgarno, L., Strauss, E. G. \& Strauss, J. H. (1982). Sequence studies of several alpha virus genomic RNAs in the region containing the start of the subgenomic RNA. Proc. natn. Acad. Sci. U.S.A. 79, 5235-5239.

Pyne, J. W. \& Hall, T. C. (1979). Efficient ribosome binding of brome mosaic virus (BMV) RNA4 contributes to its ability to outcompete the other BMV RNAs for translation. Intervirology 11, 23-29.

Strauss, E. G. \& STRauss, J. H. (1983). Replication strategies of the single stranded RNA viruses of eukaryotes. Current Topics Microbiol. Immunol. 105, 1-98.

van Kammen, A. (1985). The replication of plant virus RNA. Microbiological Sciences $2 ; 170-173$. 
